\title{
A Psychiatric Service Almost Without a Psychiatric Hospital
}

Eddie Black, Director of Nursing Services; Richard Moore, Unit Administrator; and Tony Whitehead, Consultant Psychiatrist, Bevendean Hospital, Brighton

For the past twenty years or more it has been suggested that all our large psychiatric hospitals should be closed and psychiatry transferred to the community. This idea has generated a large amount of discussion, innumerable papers and much anxiety. More recently it has become the stated objective of the Department of Health, and now every region in the country is making concrete plans to transfer psychiatry from the mental hospital to facilities in the community with the definite objective of closing down psychiatric hospitals within a measurable time. Naturally this has generated even more discussion-and even more anxiety.

Over the years various efforts have been made to establish both general hospitals' psychiatric units and community psychiatric services. Some areas have been more successful in this than others but no psychiatric hospital has yet been closed, though some have become depositories for the elderly and unwanted. Such an outcome was forecast by many of us a number of years ago and the fact that it has become a reality is neither pleasing nor acceptable.

It does appear that the present policy is going to be implemented and hence it is important that everyone in psychiatry concentrates their minds on how this can be achieved without the dire consequences forecast by some and demonstrated by others. In relation to this it might be worthwhile examining our experiences in Brighton where, in 1974, we lost our psychiatric hospital to another district and another region and have been under pressure to become self-sufficient ever since. For the past two years we have only had very limited facilities at the old psychiatric hospital, and within the next two years or so these are going to disappear completely. Thus we have become a district that has had to create and supply a psychiatric service almost without a big psychiatric hospital.

\section{Background}

For many years what is now Brighton Health District had St Francis Hospital, Haywards Heath, as its psychiatric hospital. In the district itself there was a small observation unit in Brighton General Hospital and Lady Chichester Hospital, in Hove, provided a neurosis service.

On the principle that the elderly should be the first group to be removed from the psychiatric hospital, a special service for the elderly mentally ill, which was established in 1968 , started to develop its community facilities at that time. The first stage was the establishment of a day hospital in Brighton, followed by the provision of an in-patient unit and later another in-patient unit and day hospital. A psychiatric community nurse programme was also started.
By 1982 there was, within the district, one general hospital psychiatric unit, one small psychiatric unit apart from any general hospital, and two units for the elderly mentally ill, one in the large general hospital, i.e. Brighton General Hospital, and the other one in Bevendean Hospital, which is a small general facility. This service for the elderly only covered Brighton and a little bit of the coastal strip towards Newhaven, the rest of the district still being served by St Francis Hospital. The general hospital units were still heavily dependent upon St Francis Hospital for its facilities.

\section{Developments since 1982}

In 1982 another small psychiatric unit was opened in what had been a women's hospital (New Sussex Hospital). This meant that the three psychiatric units could now provide a full acute service for the district and care for a limited number of long-stay patients.

Services for the elderly mentally ill had been self-sufficient for Brighton since 1978; now a long-term plan to establish another day hospital for the elderly in Hove has come to fruition. Plans are now being made to establish a third unit for the elderly mentally ill in Hove close to Lady Chichester Hospital-this may be provided in a local authority old people's home that is surplus to the local authority's requirements. With these two facilities the whole district would then be self-sufficient as far as the elderly are concerned. At the same time a number of plans are being made to establish a continuing care facility, which again includes a local authority home which is no longer required and the co-operation of the voluntary and private sector.

\section{Community psychiatric nursing service}

From 1982 onwards the community psychiatric nursing service has been considerably expanded; there are currently 23 community psychiatric nurses providing a service within Brighton Health Authority's Mental Health Unit. Five are employed as members of the Unit's task force for the elderly mentally ill (see below); three as members of the community team working with the elderly in the three Brighton sectors; one as a member of the drug dependency team (a subregional service); and one who works as a member of the district alcohol team (which provides a district wide service within Brighton Health Authority).

\section{The task force}

Because of the lack of local provision for the elderly in Hove and Portslade, i.e. that part of the district not covered by the Brighton units, a task force was established 
to provide help for the elderly being supported in old peoples' homes, be they local authority, voluntary or private sector facilities.

This service began on 17 September 1984. Its aim and objectives were to: (i) co-ordinate and supplement the rapid and optimum use of existing services in Hove and Portslade; (ii) to make professional expertise readily available and accessible to residential homes and the community; and (iii) to encourage and maintain a high standard of care in residential homes. This incorporates meeting the individual needs of clients and their carers. It also offers individual counselling, comprehensive information, and is a resource centre.

The task force consists of nursing, psychology and occupational therapy workers. A plan of action is devised having assessed each client's situation or training need. Through the formation of a single plan of action, consensus is reached between the multidisciplinary team members and the participation of the client; thus producing a comprehensive mode of treatment.

The task force operates on an 'open-referral' system. Apart from the primary health care team members, statutory and non-statutory organisations, a referral could also come from the client.

\section{Hove Centre for community mental health}

During this period a community mental health centre was established close to the Lady Chichester Hospital in Hove. This facility was established to provide help in detecting, managing and treating mental health problems before they develop to a stage where long-term psychiatric care is needed.

The Centre is staffed by a specialist team which includes a social worker, senior clinical psychologist, occupational therapist, community psychiatric nurse and two behavioural nurse therapists. The team is able to offer a wide range of skills and knowledge, but it can also draw on all the resources of Brighton Health Authority's mental health services (of which the Centre is a part).

The resources referred to above include treatment at home (e.g. through the CPN service), access to specialist clinics to help people with alcohol or drug addiction, longer term treatment (such as psychotherapy), in- and out-patient hospital services and day hospitals. The team also has access to the facilities of the next door Allen Centre, a mental health day unit run by East Sussex County Council's social services department.

The Centre can offer help to people with a wide range of personal difficulties including neurosis, bereavement, problems with relationships, depression, social isolation, and stress. The team may also be able to give practical help with housing problems and advise on domestic or financial matters. The team does not, however, offer daily care, nor can it provide supervision for elderly people who are confused or for people who are mentally handicapped. It is hoped to expand the range of treatment facilities offered as the mental health needs of the local community are identified, and the team sees this as part of its function in contributing towards mental health promotion, mental illness treatment and its after-care. In addition, there is a considerable emphasis upon involvement of team members in health education programmes and public relations work.

\section{Continuing care}

A continuing care team has been established which is carefully examining the needs of this group, and devising methods of providing these needs that extend from a hospital hostel unit already mentioned to various types of accommodation.

The significant lack of continuing care facilities within the district has presented a major challenge and in attempting to map out a way forward a number of factors have had to be taken into account, not least of which are the following: (i) the present services, their style and the sectorised arrangements that have now been developed; ${ }^{1,2.3}$ (ii) the recently published South-East Thames Regional Health Authority mental illness funding policy which should enable resources to be freed from two adjacent health authorities to assist in developing services locally; and (iii) the future plans to establish localised planning machinery as a next step in consolidating the present planning machinery in line with the recommendations of the MIND manifesto, Common Concern. ${ }^{4}$

To some extent recognising that 'small can be beautiful' in terms of developing a comprehensive range of facilities of a non-institutional nature for the chronically mentally ill, plans have been framed around the sectorised arrangements which have been developed in line with the establishment of small, semi-autonomous units serving local catchment populations.

The population of Brighton naturally divides into six sectors (average population, 40-50,000 residents). It is envisaged establishing multiprofessional teams to provide a service to each sector with an integrated network of facilities at the disposal of the teams, ranging from day hospitals to hospital hostels, and daily living houses (closely associated with the in-patient units/day hospital), supervised hostels in the community, cluster flats and supported bed-sit accommodation.

One of the key principles which has been adopted in deciding upon an appropriate service model is the concept that it should be promoting self-help and education for this group of people with a significant slant towards developing individualised care programmes, and a strong emphasis upon using an 'adaptation' model as a desirable philosophy underpinning the teams' approaches to improving the quality of life of each individual client. ${ }^{5}$

It is also envisaged testing a pilot scheme in one geographical sector initially, and in the first instance this would involve establishing an 18-bedded hospital hostel, six cluster flats, a 15-place 'daily living' house and a network of community support services. The pilot scheme will require a great deal of work in terms of co-ordination, particularly since the service is being developed in conjunction with voluntary agencies, housing associations, and the 
private sector. It is planned to build in evaluation mechanisms for each service element developed as part of the total scheme which will hopefully provide a very good overall picture of how effective the service is from a consumer aspect, and also from the point of view of its cost effectiveness.

\section{Other services}

There is within the district a specialist drug dependency unit, a unit for alcoholism and, of course, supra-district facilities for child psychiatry and adolescent psychiatry.

\section{Some lessons learned}

Communication, however hackneyed the expression, is all important in developing a community service. An attempt has been made to provide a communication network and this network is under constant review. In addition to communication between the mental health unit, the local social service department, the voluntary sector and the private sector, the CPN service and the Hove Centre for mental health supply information about what is going on in the community, the services' failures and possible areas for concern. Some CPNs are attached to primary care teams and thus act as an additional line of communication between hospital and general practice.

In relationship to the use of CPNs in ascertaining needs and answering these needs, it was discovered that a private hostel in Brighton filled with patients discharged from other districts was not as it should be. In agreement with the owners, a CPN became involved in the hostel providing advice and support. As a consequence, conditions in the hostel improved significantly and it is now a reasonable facility for continuing care.

Obviously continuing care is the major problem as far as establishing a proper community psychiatric service is concerned. It would appear that it is essential to conscript the help of both the voluntary and private sector. To ensure that facilities provided by these two sectors are adequate, it would seem to be essential that not only is help offered to them by way of the task force and CPN involvement, but that this involvement also encompasses some degree of monitoring. This is a delicate area, but provided that the mental health service workers are of the right quality it is possible for them to both help and monitor without causing anxieties and strife.
There are some patients who are now described as 'difficult to place patients'. This group is a problem to every district and it is not claimed that Brighton has an answer. However, the problem is being carefully explored and the help of local magistrates, the probation service, the police and other interested agencies has been obtained and concrete plans are being made to deal with this harassing problem. Even some money has been found to facilitate such plans.

\section{Conclusions}

It is obviously possible to transfer all psychiatric services from the large mental hospitals to the community. The only problem is the lack of facilities and funds. Our experience suggests that it is possible to become self-sufficient within a district without phenomenal expense, provided there is a willingness to use whatever facilities and buildings become available, and not be tied up in long and dreary discussions about establishing ideal facilities.

It is of prime importance that a network of communication is established that will, as far as possible, ensure that those patients discharged from hospital are not neglected or allowed to slip into a quality of life that would be totally unacceptable even in the most backward hospital. This can be done by creating a communication network with the social service department, the voluntary sector and any other group with an interest in mental health, plus an effective CPN service and facilities (such as the Hove Centre) where people can go directly when they are worried and concerned, either about themselves or others. We believe that failure to provide such a network will lead to many ex-patients experiencing long-term suffering and recurrent scandals that may ultimately destroy the establishment of proper community psychiatry.

\section{REFERENCES}

'Black, E. W. J., MOORE, R. W., Whitehead, J. A. (1983) A variation on a theme of Nodder. Nursing Mirror, 157, 23, p. 33.

2 _ (1983) Management after Nodder. Health and Social Service Journal, 93, 13 October, p. 1227.

3 _ _ (1984) Catching up with sector psychiatry. Health and Social Service Journal, 94, 6 September, p. 1062.

'National Association for Mental Health (1983) Mind's Manifesto: Common Concern. London: MIND.

${ }^{5}$ Roy, C. (1976) An Adaptation Model. Englewood Cliffs, New Jersey: Prentice Hall.

\section{'Violence and Victims'}

Violence and Victims is a new quarterly journal which will be launched in Spring 1986. Its aim is to provide a forum for the latest developments in theory, research, policy, clinical practice, and social services in the area of interpersonal violence and victimisation. The journal seeks to facilitate the exchange of information on this subject and invites articles from relevant fields including psychology, sociology, criminology, law, medicine, psychiatry, social work, and nursing.
Authors should send four copies of their submission (following American Psychological Association Style, 3rd ed.) To: Angela Browne, Editor-in-Chief, Violence and Victims, Family Research Laboratory, Horton Social Science Center, University of New Hampshire, Durham, NH 03824, USA. Information concerning subscriptions is available from Springer Publishing Company, 536 Broadway, New York, NY 10012, USA. 